\title{
The Teacher-Student Conflict and Its Educational Implications
}

\author{
Yajun Fang \\ Department of Finance, Shanghai University of Finance and Economics, Zhejiang College, Jinhua, China \\ Email: 1287946066@qq.com
}

How to cite this paper: Fang, Y. J. (2021). The Teacher-Student Conflict and Its Educational Implications. Open Journal of Social Sciences, 9, 348-366.

https://doi.org/10.4236/jss.2021.98024

Received: July 29, 2021

Accepted: August 17, 2021

Published: August 20, 2021

Copyright $\odot 2021$ by author(s) and Scientific Research Publishing Inc.

This work is licensed under the Creative

Commons Attribution International

License (CC BY 4.0).

http://creativecommons.org/licenses/by/4.0/

\begin{abstract}
The teacher-student conflict is an important issue that educators pay attention to. The study of the teacher-student conflict has important social and practical significance. The article explains the meaning of the teacher-student conflict of an acquired good fortune, the existence by cooperation and the test of the relationship. It points out the life impact of the teacher-student conflict on the teacher-student relationship and teacher-student interaction. And it reveals the educational implications of the judgment of source of the teacherstudent conflict, cooperation enhancement and harmonious construction.
\end{abstract}

\section{Keywords}

The Teacher-Student Conflict, Competition, Cooperation, Education

\section{Introduction}

The relationship between people is an important issue of existentialism. The existentialist Sartre believes that "others are hell" and the relationship between people is opposite. But the existentialist Buber believes that the relationship between people is the relationship between "me and you". Buber's views are accepted by most educators. As the philosopher Martin Buber believed, relationships are the true essence of education. "The relationship in education is a purely dialogue relationship" (Buber, 1965). The teacher-student relationship is the main dialogue relationship in education. "To make the dialogue between teachers and students go on, teachers must properly handle the conflicts between teachers and students" (Lu, 2012). Therefore, paying attention to the problem of teacher-student conflict has very important social and practical significance. But the question is, what does the teacher-student conflict mean? How does the teacher-student conflict affect the lives of teachers and students? Facing the conflict between teachers and students, what can education do? 


\section{The Meaning of the Teacher-Student Conflict}

The traditional view is that there are three views on the concept of education. First, education is about instilling something into students. Second, education is to improve students' adaptation to the future. Third, education is to increase students' problem-solving abilities. Therefore, traditional education methods are aimed at the realization of some external goals. The teacher-student relationship under traditional education is a relationship of domination and obedience. "Teachers spend a lot of time controlling students, and students also come up with various ideas to deal with teachers" (Lu, 2012). In this way, conflicts between teachers and students are prone to arise. However, modern education attaches importance to treating students as human beings. In the teacher-student relationship, it emphasizes the establishment of a close, trusting and caring teacher-student relationship. "Teachers and students should stay together for several years through mutual agreement. It should take time to build trust so that the advice, care and teaching given by teachers can be accepted, understood and appreciated by students" (Noddings, 2017). On the one hand, influenced by conservative educational thinking and outdated teaching concepts, it is always difficult for some teachers to break away from the shackles of traditional education. The teacher-student relationship of control and resistance is still emerging in the classroom, and the teacher-student conflict is still maintained. On the other hand, the teacher-student relationship is not equal. Teachers should bear the responsibility of criticizing and educating students for their bad behaviors because they have to pay more attention, care and care to their students. Many students have difficulty understanding this point. Therefore, conflicts between teachers and students due to misunderstandings often exist.

So, what exactly is a teacher-student conflict? In order to explain the connotation of the conflict between teachers and students, first explore the meaning of conflict. American sociologist Parker believes that conflict is one of several basic forms of limited human interaction. "Only where there is conflict can there be behavioral awareness and self-awareness; only in such a place can there be conditions for rational behavior" (Coser, 1989). In Parker's view, conflict can help self-awareness gain and organize the composition of society. However, contemporary sociologist Parsons tends to believe that "conflict is basically a 'pathological', conflict mainly has destructive, divisive and anti-functional consequences" (Coser, 1989). The function of Kosai's social conflict. It can be seen that the function of conflict is full of controversy, and conflict is manifested in the interactive behavior or independent state between the relationship subjects. According to this, returning to the field of education, the conflict between teachers and students can be understood as the interaction or opposition between teachers and students. As related research shows, "the teacher-student conflict refers to the implicit or open rejection, resistance, and opposition between teachers and students due to certain differences." (Zhao, 2021). However, the social nature of the teacher-student relationship determines the teacher-student conflict is not a 
fixed interpersonal existence., But a kind of developmental interpersonal existence, which contains at least the connotation of a three-fold progressive progression: the teacher-student conflict is an acquired good fortune, not a congenital endowment; the teacher-student conflict exists by cooperation, not by competition; Conflict is a test of relationship, not control of people.

\subsection{The Teacher-Student Conflict Is an Acquired Good Fortune, Not a Congenital Endowment}

When it comes to the teacher-student conflict, people will not be curious: where does the teacher-student conflict come from? It is born or born. The occurrence of human relationships often depends on two levels of human nature and the environment in which people live. From the perspective of human nature, the conflict between teachers and students should be the product of mutual disputes between the good and evil of human nature. If the teacher-student conflict is considered innate, then it is very likely that human nature is evil. Under the theory of evil nature, there is no good end between people. When people meet, there will be hatred and hostility, without any will to reconcile. If so, it also means that there is no goodwill between people. Reflected in the field of education, the conflict between teachers and students is innate, which means that teachers and students are innate hatred and enemies. They will regard each other as natural enemies. There is no phenomenon of friendship between teachers and students. The proposition that conflict is innate seems to be an unchanging theorem, but the friendship of the world completely breaks this theorem. Because in life, on campus, in the classroom, sincere dialogue and friendly interaction between teachers and students are indeed taking place. In other words, the myth of the never-goodwill exchanges between teachers and students was broken, causing the self-contradiction of the proposition that the conflict between teachers and students was born. From the perspective of real life, the teacherstudent conflict is not innate. Some people may ask: If human nature is good, will the teacher-student conflicts be born? People who hold this kind of question will think that everyone's human nature is good, but everyone is unwilling to be kind to others. People are only himself and only suitable for himself. Human existence is self-existence. Man is like living in a cave. Mirrors are displayed everywhere in this cave. Through these mirrors, man can only see himself. Obviously, this kind of human existence situation is an idealistic situation, which does not exist in reality. Even Buddhist monks cannot completely escape from the world. That is to say, even if human nature is good, people will no longer exist if they leave the will of reality, but live in nothingness. It can be seen that no matter whether human nature is evil or good, human beings are realistic and not given by nature. In the circumstances of life, the conflict between teachers and students is also realistic, not inborn. So, from the standpoint of human nature, the conflict between teachers and students is the result of life, but it is actually the result of acquired human reality. From the perspective of people's environment, the conflict between teachers and students should be the result of the interaction 
between people and their environment. The interaction between people and the environment is often reflected in two aspects: one is the mutual adaptation between people and the environment, and the other is the inability of people to adapt to the environment. If the interaction between people and the environment is manifested in the mutual adaptation of people and the environment, it indicates the mutual adaptation of the teacher-student and teacher-student interaction environment. It is generally believed that the mutual adaptation of people and their environment will generally bring good results or expectations. Reflected in the relationship between teachers and students, the mutual adaptation between teachers and students and their environment will bring harmony and consistency. In other words, the mutual adaptation between teachers and students and their environment will promote harmony between teachers and students. However, according to this logical deduction, the condition of the conflict between teachers and students is reflected in the inability of people and the environment to adapt to this aspect. However, this is not the case. Even if the mutual adaptation between teachers and students and the environment is absolutely true, there will be conflicts between teachers and students. The occurrence of the teacher-student conflict does not entirely depend on the relationship between humans and the environment. In other words, the adaptation of humans to the environment cannot constitute a criterion for the emergence of the teacher-student conflicts, excluding all subjective human factors, there may be some. The third type of environmental impact, this environment is a kind of external environment, a kind of other environment, different from my environment and yours. In his environment, the teacher-student conflict does not exist between me and you, but between me and you. When people say that a relationship is within the subject, then this relationship is inseparable from the subject, but exists in the subject. It is not affected by the subject's external environment. For the subject, it is with the subject. What is born is born with. Conversely, if a relationship is between the subject, then this relationship keeps a distance from the subject and exists relative to the subject. It is easily controlled by the subject's external environment. For the subject, it is the product of the external environment acting on itself, Is epigenetic. With this kind of logical vision, we can observe the characteristics of the teacher-student conflict. First of all, the teacher-student conflict is a manifestation of teacher-student relationship, a main reflection of teacher-student life, and it affects the quality of teacher-student life. Secondly, the teacher-student conflict is a relationship that occurs between teachers and students. It does not lie in the main body of the teacher and the student, but separates from the teacher and student themselves. Finally, the teacher-student conflict is in an environment outside the subject, deeply affected by his environment, and not restricted by my and your environment. All in all, the teacher-student conflict is external rather than internal. Therefore, from the perspective of people's environment, the teacher-student conflict is epigenetic, but it is actually the result of the acquired environment's effect on people.

It can be seen that from the standpoint of human nature and the environment, 
the teacher-student conflict is an acquired good fortune, not a congenital endowment. In other words, the conflict between teachers and students is not born with human beings, and people do not come to this world with conflicts. The conflicts between teachers and students arise in the acquired environment. Some people may question this view, thinking that human beings, as advanced animals, are born with a biological hostile instinct. It is also because of this hostile instinct that people who come to this world and live in this world will inevitably conflict with others. Just like Simmel's point of view: “The cause of conflict is not the result of external factors, but the result of human actors' innate biological factors. Conflict is not only a product of conflict of interest, but also a reflection of hostile instinct" (Huang, 2003). Qi Meier pointed out the biological hostile instinct of human beings and believed that the hostile instinct of human was the cause of conflict. Based on this, some people will infer that the human conflict is an innate endowment conclusion, thus denying the conclusion that the teacher-student conflict is an acquired good fortune. However, this kind of inference is one-sided because it leaves the context in which the conflict between teachers and students is the result of social interaction between teachers and students. Without the social background, the teacher-student conflict will lose a position to rely on, the teacher-student conflict will be difficult to occur, and the hostile instinct of the person who caused the teacher-student conflict will not be released. In addition, conflicts between teachers and students generally involve both subjects, and the interaction between subjects is a kind of social behavior, which can only happen the day after tomorrow. Therefore, the teacher-student conflict is an acquired good fortune, not a congenital endowment.

\subsection{The Teacher-Student Conflict Exists by Cooperation, Not by Competition}

First of all, understanding the teacher-student conflict from the standpoint of teacher-student competition is an important way to analyze the teacher-student relationship. Generally speaking, people think that the conflict between teachers and students is caused by the competition between teachers and students, and they survive by competition. Combining the manifestations of the teacher-student conflict, there are often three competing manifestations of the teacher-student conflict: First, it is manifested as a verbal attack. Second, it is manifested as physical confrontation. Third, it is manifested as a patchwork of concepts. It can be imagined at the scene of the teacher-student conflict: in the classroom, a student sitting in the front row is sleeping in the teacher's classroom. At this time, the observant teacher pulled the sleeping student's arm forcefully, awakened the student, and asked the student to stand up. Out of shame, the student complied with the teacher's request. After a while, the teacher found the student. It started to fall asleep again, so the teacher was completely annoyed. Without suppressing his temper, he directly ordered the students to "get out of the classroom", and the students who were still asleep reluctantly walked out of the classroom. At this time, a classmate on one side directly slapped the table to express anger. In 
his opinion, the sleeping classmate was silent in class, and there was no hindrance to others' learning. The teacher's practice directly deprived the sleeping classmates of their personal rights. From the teacher's point of view, the sleeping student not only did not follow the persuasion, but instead allowed himself to do whatever he wanted. There was no strict requirement for his own learning. Their behavior directly harmed the atmosphere of the class and greatly interfered with his teaching. It can be found that when a teacher-student conflict occurs, there are verbal attacks and physical confrontations between teachers and students, and we can also experience the misconceptions of the same class sleeping behavior between teachers and students.

Secondly, seeking a form of cooperation from the conflict between teachers and students is an important way to discuss the relationship between teachers and students. If you want to explore the form of cooperation between teacher and student conflict, you must trace the function of the conflict. In the book "The Function of Social Conflict", Coser mentioned the function of conflict, thinking that conflict can be used as both a means and as a goal. "The difference between conflict as a means and conflict as a goal implies a difference in reality conflict. Criteria that conflict with non-reality" (Coser, 1989: p. 35). He further pointed out that actual conflict is to achieve a specific goal, and non-realistic conflict is to use conflict as a means of releasing tension. Therefore, from the perspective of goals and means, there are two forms of cooperation in the teacher-student conflict: one is the determination of a common goal, and the other is the replacement of conflicting means. The determination of the common goal has found the source of the goal for the teacher-student conflict. If the teacherstudent conflict is caused by the external environment, then disputes will arise within the teacher-student group, and the group members will unite through the debate to establish a common goal, thereby consolidating the teacher and student Unity and cooperation within the group. As Coser said: "If external threats cause conflicts within the group, it shows that the issue of internal disputes is vital to every member of the group, enough to cause internal fighting within them, which is completely different from Group members just don't care, or are indifferent to external threats." (Coser, 1989: p. 79). There is a prerequisite that Coser said is that before the arrival of external threats, there is a consistent structure within the group. If the previous wishes within the group are inconsistent, then the external threat is not a repair agent to consolidate group unity and cooperation, but a catalyst to accelerate the disintegration of the group. The replacement of conflict means finds a cooperation path for the teacher-student conflict, that is, the teacher-student conflict is to find a way to cooperate through the replacement of conflict means. When both teachers and students face the same conflict and are powerless to each other, the desire for cooperation between teachers and students arises. However, it is difficult to achieve teacher-student cooperation with only one conflict method between teachers and students. In this process, the participation of new conflict methods is also needed to replace the original 
conflict methods and promote good the teacher-student conflicts. To turn, it can be seen that there are both teacher-student competition and teacher-student cooperation in the teacher-student conflict. In other words, teacher-student competition and teacher-student cooperation both exert their own influence in the teacher-student conflict. However, the question of what kind of force it relies on why the teacher-student conflict can survive still needs to be explored.

Finally, the teacher-student conflict is a relationship that occurs between teachers and students that is both competitive and cooperative. Is this relationship a kind of existence? When it comes to problems of existence, people are exploring the reality of existence. That is, people want to prove that a thing exists, and people want to figure out when, where, and how it exists, and judge whether the thing is real. Reality includes not only the existence of things being directly sensed, but also the existence of things being separated from the senses. For the existence of things by direct senses, people can feel its existence through the naked eyes, touch and other senses. For the existence of things that are separated from the senses, people can prove its existence through methods such as description, association, and comparison. Take the table in the room as an example. People confirm that the table exists, usually because people can see its existence with the naked eye, or feel its existence by touching it. And how do people confirm the existence of the senses outside the table? When people pass by a room, they suddenly hear the sound of someone tapping a table in the room. At this time, people can figure out the fact that there is a table in the room by judging and comparing people's previous experience of tapping the table and listening to the sound. The philosopher Bertrand Russell put forward the concept of universals in the book "Questions of Philosophy, Religion, and Science". He believes that "a universal is the kind that can be shared by many special things, and has such some something special" (Russell, 2016). In Russell's view, the relational entity is a kind of universal, which is different from the so-called physical object, as well as from the mind and sensory materials. Relational entity is the universal represented by verbs and prepositions, which is different from the universal represented by adjectives and nouns. Russell believes that in the past philosophers paid too much attention to the universals expressed by adjectives and nouns, and often ignored the universals expressed by verbs and prepositions. In other words, Russell pointed out the paranoia of past philosophers regarding the existence of qualitative entities and relational entities. On the issue of proving the existence of entities, Russell believes: "People cannot strictly prove the existence of entities such as nature, that is, they cannot prove the existence of adjectives and nouns; but people can prove that the relationship is inevitable. Existence, that is to say, can prove the universal existence generally represented by verbs and prepositions" (Russell, 2016). Russell cited the existence of Bai, a co-relative entity, to prove it. In contrast to the problem of the teacher-student conflict, the teacher-student conflict exists as a manifestation of the teacher-student relationship.

But the question is, does the existence of the teacher-student conflict rely on 
competition or cooperation? This question involves two aspects. One is why the conflict between teachers and students exists, and the other is how conflicts between teachers and students exist. First of all, from the point of view of the causality of the teacher-student conflict, the teacher-student conflict comes from competition, and the form of cooperation in the teacher-student conflict also comes from competition. However, from the perspective of the outside and inside, the teacher-student conflict really occurs in the real world and exists as a visual phenomenon. It is impossible to know whether it exists internally because of competition or cooperation. Does this mean that people cannot imagine the existence of the teacher-student conflict? The answer is definitely not the case, because the reason why human beings exist in the world must have their own mechanisms of existence. If people think that animals will replace humans and exist, then people have reason to infer that animals defeat humans through biological competition, because people see the existence of animals for survival. If humans also conquer animals through biological competition, then the existence of humans is just a bullying against animals. Humans themselves have no social meaning, because what people see is that humans are not living. At the scene of questioning the conflict between teachers and students, people can't help but wonder where the cooperation will be hidden if competition is willing to arise. Secondly, from the perspective of the process of the teacher-student conflict, in classroom conflicts, people generally think that the teacher-student conflict continues because the teacher-student competition has not yet ended. In other words, people generally think that the competition is the cause of the conflict. The motivation of the teacher-student conflict. Assuming there is no competition, will the teacher-student conflicts still exist? At the moment, conflicts between teachers and students are constantly occurring in the classroom, and the scenes that occur are not the same. In an educational scenario, returning to the "get out of the classroom" case, the teacher-student conflict stems from the frontal confrontation between teachers and students caused by sleeping in class. On the surface, the teacher-student conflict is just a competition between The teacher and the "chivalrous" classmates., the teacher-student conflict exists by virtue of competition. It stands to reason that once the competition disappears, the teacher-student conflict will stop. In fact, when competition ceases to exist, the teacher-student conflict will continue. In order to take the overall situation into consideration and stop the competition with the "chivalrous" classmates, the teacher-student conflict has not disappeared, but hidden in the clouds. However, teachers compete for the learning rights of other students in the class, and "chivalrous" students compete for the learning rights of sleeping students. Although teachers and "chivalrous" classmates compete in different service subjects, the target objects of the competition are the same, that is, both are for the defense of learning rights. It can be seen that the willingness to cooperate plays an important role in the conflict between teachers and students. From this perspective, the conflict between teachers and students depends on cooperation. It is precisely because 
the teacher and the "chivalrous" classmates have a desire to cooperate with each other, but this desire has not been effectively realized, pushing each other into a deep insufficiency, and continuing the teacher-student conflict behavior. In another educational scenario, suppose that the sleeping classmates confront the teacher head-on, and direct competition occurs. In order not to affect the learning process of the class classmates, the teacher stops competing with the sleeping classmates and chooses to let it go. At this time, the competition is actually over, but the teacher-student conflict is still happening quietly. This is enough to show that it is not competition that maintains the conflict between teachers and students. From the perspective of goals, people prying into this event will find that teachers and sleeping classmates have a common goal, which is to pursue free will. In order not to be disturbed, teachers want to teach freely, and sleeping students want to relax freely, which confirms the willingness to cooperate between teachers and sleeping students in terms of consistency. In this process, the conflict between teachers and students is invisible Supported by cooperation. Therefore, the teacher-student conflict exists by cooperation, not by competition.

\subsection{The Teacher-Student Conflict Is a Test of the Relationship, Not the Control of People}

In the field of education, when the teacher-student conflicts occur, the characteristics of teachers and students as human beings are revealed. Both parties to the conflict will also regard each other's dissatisfaction because of their respective positions, resulting in the possibility of subtle changes in the teacher-student relationship. In classroom conflicts, when people find signs of opposition between teachers and students, there is an insurmountable gap between teachers and students. From the perspective of the goal of the teacher-student conflict, is the teacher-student conflict a test of the relationship or the control of people? To clarify this problem, it is necessary to analyze and discuss the object of the conflict between teachers and students. As mentioned earlier, the teacher-student conflict is a teacher-student relationship, which includes teacher-student confrontation and teacher-student cooperation. In the teacher-student confrontation, whether the conflict between the teacher and the student is manifested as a verbal attack, a physical confrontation, or a dislocation of ideas, either party will involve the teacher and the student in the competition, causing tension in the teacher-student relationship. There is a kind of tension in the relationship between the teacher and the student. Hope of a broken relationship. In this scenario, the teacher-student conflict is a threat to the relationship. However, in teacher-student cooperation, whether the conflict between teachers and students is manifested in the determination of a common goal or the replacement of conflict means, each other will also bring teachers and students into the cooperation, resulting in a harmonious relationship between teachers and students. There is a kind of harmony within harmony. The relationship is terrible. In this scenario, 
the teacher-student conflict is the solidification of the relationship. It can be seen that excluding the influence of people, the conflict between teachers and students may threaten or freeze the relationship between teachers and students, which is a test of the relationship. However, the conflict between teachers and students is a conflict between teachers and students, and it is a conflict between people. Therefore, people can't help but wonder: Will the conflict between teachers and students bring about "war" and results between people? From the standpoint of possession, people want to figure out whether the conflict between teachers and students can achieve control over people. If the purpose of the teacher-student conflict is to control people, then the nature of the teacher-student conflict is very similar to the nature of capturing the enemy through war, because the purpose of war is to achieve conquest and control, and war must be accompanied by bloodshed and sacrifice. On the other hand, the teacher-student conflict in the classroom is just a behavior phenomenon that occurs in the classroom. It does not achieve the desire to conquer control and the result of bloodshed and sacrifice. It is only a behavioral event that occurs at the level of interpersonal relationships. Therefore, the teacher-student conflict cannot be compared with war. War is the destruction of relations and the control of people, while the conflict between teachers and students is a test of the relationship, not the control of people.

The teacher-student conflict is a positive conflict behavior that occurs between teachers and students. It will inevitably cover the ideas and positions of both parties in the conflict, as well as the attitudes and values held by the teachers and students to adhere to their own words and deeds in the conflict. In a conflict classroom, when a conflict between teachers and students breaks out, teachers and students will face a dilemma: on the one hand, they want to gain benefits for themselves in self-protection or group maintenance, and on the other hand, they don't want to have them because they are afraid of others leaving or being affected by others. Control and worry about it. The ambivalence of conflicts between teachers and students is closely related to the interpersonal environment faced by conflicts between teachers and students. First of all, for teachers and students in deep conflict, they want relationships but are afraid of relationships. In relationship theater, they are both actors and audiences. In the conflict between teachers and students, they acted as themselves and viewed others. The relationship between self and others is full of trials. Secondly, returning to the scene of the conflict between teachers and students, teachers and students are eager to control but difficult to control. Teachers and students appear as human beings and lack the strength to think about the meaning of people themselves in the conflict. Therefore, in the conflict between teachers and students, teachers and students cannot control themselves. Others are in the relationship between self and each other. If conflicting teachers and students want to control others, but others cannot follow the self-control, therefore, conflicting teachers and students cannot control each other. From the standpoint of the environment of the 
teacher-student conflict, when the environment of the teacher-student conflict is superior, the psychology of conflicting teachers and students is positive, and the goal of the teacher-student conflict is to move towards cooperation. When the environment of the teacher-student conflict is inferior, the conflicting teacher Students' psychology is negative. The goal of the teacher-student conflict is to compete. Whether it is cooperation or competition, it is a verification of the teacher-student relationship. It has nothing to do with the laissez-faire or control of people. In other words, conflict between teachers and students is both Can't control oneself, can't control others, the teacher-student conflict can not achieve control over people, and there is no control result at all. It can be seen that conflicts between teachers and students always occur in the relationship between the conflicter and others. This relationship also becomes unstable due to the development of the situation or degree of the conflict between teachers and students, but the only certainty is that the occurrence of the conflict between teachers and students is not Occurs against people, and people do promote the process of the teacher-student conflict all the time.

In summary, since the teacher-student conflict cannot control people and relationships, any changes in people and relationships become uncertain. In other words, the effect of the teacher-student conflict on people and relationships is also uncertain. Therefore, the teacher-student conflict has a test shadow on people and relationships, and there is no determination to control them. In other words, after it is determined that the teacher-student conflict is an acquired good fortune and survives by cooperation, the teacher-student conflict enters an influential circular vortex, located at the periphery of the vortex, and in the center of the vortex is the teacher and student. Relationship, the teacher-student conflict revolves around the teacher-student relationship and examines the teacher-student relationship, acting as a supervisor.

\section{The Impact of the Teacher-Student Conflict on the Lives of Teachers and Students}

The teacher-student conflict is a kind of antagonistic behavior that occurs in the acquired life of teachers and students, including the competition and cooperation between teachers and students. It can be seen that the teacher-student conflict cannot bypass the teacher-student life. From the perspective of the duration of the teacher-student conflict, the longer the teacher-student conflict lasts, the more teachers and students must put in more energy for this, and the quality of life between teachers and students will be more affected. As a result, the teacher-student relationship is on the verge of rupture. On the contrary, it is unlikely that the teacher-student relationship will rupture. In addition, the longer the teacher-student conflict lasts, the less and less dialogue between teachers and students, which will create obstacles to the communication between teachers and students. On the contrary, teacher-student interaction can still be carried out. From the perspective of the space for teacher-student conflicts, when the space 
for conflicts expands, the original conflicts will have opportunities for growth and new conflicts will develop. Teachers and students will be forced to be involved in the danger of being surrounded by teacher-student conflicts, resulting in teacher-student conflicts. The tension of the relationship. On the contrary, the teacher-student relationship will move towards relaxation. In addition, the space for teacher-student conflicts expands, and the dialogue between teachers and students is full of uncertainty, which will lead to a crisis of trust between teachers and students and limit the normal exchanges between teachers and students. On the contrary, the possibility of communication between teachers and students increases. Therefore, the development of the teacher-student conflict affects the development of teacher-student relationship and the progress of teacher-student communication. To clarify the impact of the teacher-student conflict on teacher-student life is conducive to better thinking about the evolution of teacherstudent relationship and ruminating teacher-student communication behaviors and activities.

\subsection{The Teacher-Student Conflict Affects the Development of the Teacher-Student Relationship}

The teacher-student conflict is a manifestation of the teacher-student relationship and affects the development of the teacher-student relationship. In the conflict between teachers and students, there are not only competition between teachers and students, but also cooperation between teachers and students. When the teacher-student conflict is manifested as the competition between teachers and students, the relationship between the subjects of the teacher-student conflict is mutually antagonistic. The teacher-student relationship at this time is full of aggressive teacher-student relationship. When the teacher-student conflict is manifested as the mutual cooperation between the teacher and the student, the relationship between the teacher and the student is hand in hand with each other, and the teacher-student relationship at this time is a collaborative teacher-student relationship. Specifically, the development of the teacher-student relationship has two development directions for good and bad. The teacher-student conflict will play a role in promoting the development of the teacher-student relationship. If the teacher-student conflict promotes the development of the teacher-student relationship for good Direction development, then both teachers and students are beneficiaries of the conflict between teachers and students. People's attitude towards the teacher-student conflicts will also change immediately, and they will no longer follow traditional thinking to label the teacher-student conflicts badly. In this case, the teacher-student conflict can defend its own meaning and value, and the teachers and students participating in the teacher-student conflict can also defend their own activity value and life meaning. If the teacher-student conflict pushes the teacher-student relationship to a bad development direction, then both the teacher and the student are victims of the teacher-student conflict. People will still oppose and criticize the teacher-student conflict according to traditional thinking, and people will express hatred and hatred for 
those who participate in the teacher-student conflict. In this case, the teacherstudent conflict no longer reflects on their own ugly behavior, and the teachers and students participating in the teacher-student conflict will not truly regret their stupid behavior, or that they have long been determined. Prepare not to look back. In the former promotion, the teacher-student conflict plays the role of a contributor. It aims to promote the construction of a harmonious teacherstudent relationship between teachers and students, and enhance the quality of life and happiness index of teachers and students. In the latter kind of advancement, the teacher-student conflict plays the role of destroyer, which widens the distance between the teacher and student and hinders the construction of a harmonious teacher-student relationship. As a result, the teacher-student life becomes bleak. The happiness of life becomes out of reach. Therefore, how the teacher-student conflict advances will have an obvious impact on the development of the teacher-student relationship.

\subsection{The Teacher-Student Conflict Is Related to the Conduct of Teacher-Student Interaction}

Humans are socialized animals, and their interactions affect the process of human socialization. The teacher-student conflict is the behavior of both teachers and students in the interaction between teachers and students, and it is related to the progress of the interaction between teachers and students. The teacher-student conflicts often have two functions in teacher-student interactions. One is to enhance the interaction between teachers and students, and the other is to hinder the interaction between teachers and students. When the teacher-student conflict is manifested as a teacher-student competition, there is a confrontation between teachers and students, then the teacher-student conflict at this time plays a role in hindering teacher-student interaction. In this situation, the trust between teachers and students is in crisis or even lacking, and the desire and ability to love between teachers and students have also been lost, and the lives of teachers and students have never been divergent. When the teacher-student conflict is manifested as teacher-student cooperation, there is a story of mutual cooperation between teachers and students, then the teacher-student conflict often plays a role in enhancing teacher-student communication. Under such circumstances, teachers and students are always full of trust, there is a cooperative love and strength between teachers and students, and even a common mission of pursuing excellence. The life of teachers and students is positive and full of sunshine. In the conflict classroom, people can find that when the teacher-student conflict occurs in the form of teacher-student competition, the nature of the teacher-student interaction changes immediately, or even stops just now. Just like the conflict between the class teacher and the "sleeping" classmates, what it brings to each other is that the interaction between teachers and students stops at the teaching site. When the teacher-student conflict occurs in the form of teacher-student cooperation, the nature of the teacher-student interaction has not changed, but has been strengthened. This can be confirmed by the argument 
that the conflict consolidates group relations by enhancing the union of members. Therefore, for the teacher-student conflicts that promote personal interests, it becomes very difficult for teacher-student interactions, while for the teacher-student conflicts that promote group unity, teacher-student interactions continue to increase. In other words, whether the teacher-student interaction can be carried out smoothly does not lie in whether the teacher-student conflict occurs, but the nature and characteristics of the teacher-student conflict that occurs. This is related to the significance and value of the teacher-student interaction life. The key point is also the fundamental guarantee for the construction of a teacher-student learning community based on cooperation and love. Therefore, the teacher-student conflict is related to the conduct of teacher-student communication.

\section{The Educational Implications of the Teacher-Student Conflict}

Since the teacher-student conflict affects the development of teacher-student relationship and teacher-student interaction, it is related to the progress of teacher-student life. "The result of the conflict between teachers and students is not purely negative. If handled properly, it has educational value" (Lu, 2012). Therefore, education under the perspective of the teacher-student conflicts needs to face the challenges brought about by conflicts between teachers and students from the perspectives of conflict source analysis, conflict phenomenon representations and conflict relationship changes, so as to construct a harmonious teacher-student relationship, promote the growth of teachers and students, and create a good life for teachers and students.

\subsection{Teachers Investigate and Judge the Source of the Teacher-Student Conflicts, and Coordinate the Participation of Multiple Subjects}

When the teacher-student conflict really occurs in the educational field, educators often think about the source of the teacher-student conflict. As an important representative of educators, teachers are also an important subject of teacher-student conflicts. They have more responsibilities and obligations to clarify the source of teacher-student conflicts in order to enhance the care for students. Since the teacher-student conflict is an acquired good fortune, where is the source of this good fortune? When people face the problem of the teacher-student conflict in daily life, have people thought about the source of the conflict? Does it stem from a certain behavior or action of teachers and students? Or is it due to differences in the living habits and styles of teachers and students? Or is it due to differences in the thinking and values of teachers and students? Going back to the teacher-student conflict case of "getting out of the classroom", people can examine the source of the teacher-student conflict: in the entire case, there are two conflicts between the teacher and the student, and one conflict is the teacher and the sleeping classmate. This conflict is a direct conflict between teachers and 
students, and the other conflict is a conflict between teachers and students who "cannot be used to". This conflict is an indirect conflict between teachers and students. In the first conflict, the teacher's class and the sleeping classmate's dormant behavior caused the teacher-student conflict. In the view of the teacher, it is the student's duty to listen carefully to the lectures, and the students are not responsible for the students themselves when they sleep openly in the class. From the eyes of the sleeping classmates, sleeping in class is beyond their control, and sleeping is one thing. This kind of unconscious behavior. The indifference of the sleeping classmates caused great dissatisfaction among the teachers in the class, which led to the occurrence of the teacher-student conflicts. It can be seen that the source of the teacher-student conflict here is the sleeping behavior of the sleeping classmates. In the second conflict, the ordering behavior of the teacher and the angry behavior of the "unfamiliar" classmates caused a conflict between teachers and students. In the view of the teacher, the indifferent behavior of the sleeping classmate to the teacher's kind reminders interferes with the normal classroom teaching order, and ordering them to "get out of the classroom" is to maintain the classroom teaching order. In the eyes of the "unusable" classmates, sleeping classmates do not hinder others' learning in the classroom, and there is no interference with the order of classroom teaching. In his opinion, the ordering behavior of the teacher is intolerable. The teacher-student conflicts caused by the behavior of the sleeping classmates "getting out" of the classroom formed between the teacher and the "not used to" classmates. The source of the teacherstudent conflict here is the difference in thinking and value between teachers and students on what is a normal teaching order. In daily educational activities, conflicts between teachers and students are inevitable. It is important for teachers to stay calm and calm when a the teacher-student conflict comes. Sort out the history of conflicts between teachers and students, and study and judge the source of conflicts between teachers and students. Once the source of the conflict is found, with the participation of the teacher group, school and community parents, a joint force is formed to resolve it collaboratively. Of course, the teacher-student conflict is not necessarily negative, it also has a positive side. Therefore, before dealing with the teacher-student conflict, teachers need to have a scientific analysis and understanding of the teacher-student conflict. If the main cause of the teacher-student conflict is caused by the teacher, it can be resolved with the participation of the teacher group and the school. If the main cause of the teacher-student conflict is caused by the students, it can be resolved with the participation of the school and the community parents. If the main cause of the teacher-student conflict is caused by the teachers and students together, it can be resolved with the participation of the teacher group, school and community parents.

\subsection{Schools Insight into Teacher-Student Competition and Strengthen Teacher-Student Cooperation}

The teacher-student conflict has both competition and cooperation. Then, it is 
worth exploring which is more important between competition and cooperation in the conflict between teachers and students. Because competition and cooperation are an irreconcilable pair of contradictions, As the main body of the school, the school has the obligation to guide teachers and students to correctly view the relationship between competition and cooperation, has the responsibility to guide teachers and students from competition to cooperation, and has the ability to guide teachers and students to be good through educational life. The proportion of competition and cooperation in the teacher-student conflicts will also have a certain impact on the teacher-student relationship. When the teacher-student conflict is more manifested as teacher-student competition, whether it is manifested as a physical confrontation or a confrontation between language and concept, teachers and students are labeled as fighting each other and branded as hostility. Inside the teacher-student conflict, there will be a lack of rich teacherstudent emotions, and outside the teacher-student conflict will lead to the breakdown of a good teacher-student relationship, which is obviously very inconsistent with the educational activities that advocate "ethics and cultivating people". When the teacher-student conflict is more manifested as teacher-student cooperation, whether it is manifested as the determination of the common goal of the teacher and the student or the replacement of the teacher-student conflict means, the teacher and student will be regarded as willing to cooperate, and the teacher-student cooperation will lead The meanings given to teachers and students are positive. Inside the teacher-student conflict, there will be a strong spirit of cooperation between teachers and students, and outside the teacher-student conflict, it will trigger the psychological effect of teacher-student community social cooperation and the role model effect. In the educational context, how to resolve the teacher-student conflict, eliminate the adverse effects caused by the teacher-student conflict, and maintain the positive effects caused by the teacher-student conflict depends on how people treat the competition and cooperation in the teacher-student conflict correctly. Once people only focus on the teacher-student competition, what people can see is the distortion and evil of human nature in the teacher-student conflict, the cruel and ruthless struggle between teachers and students, and the teacher-student relationship is bad and irreversible. On the contrary, what people can see is the perfection and indispensability of humanity in the conflict between teachers and students, the cooperation between teachers and students is irreplaceable, and the relationship between teachers and students is absolutely harmonious and unquestionable. These two ways of looking at the teacher-student conflicts are undesirable, because any the teacher-student conflict involves competition and cooperation, and attempts to conceal or eliminate the influence of one party by magnifying one party are unscientific. From the perspective of education, combined with the development trend of world education, the standpoint of cooperation greater than competition is in line with the characteristics of the times and its educational significance to people. Therefore, in understanding the problem of the teacher-student conflict, schools should 
look into the teacher-student competition and strengthen teacher-student cooperation. While vigorously advocating teacher-student cooperation, they should also pay attention to the impact of teacher-student competition. When dealing with the teacher-student conflicts, schools should pay more attention to the meaning and value of teacher-student cooperation in the teacher-student conflicts, and avoid being brought into the misunderstanding of reasonable conflicts caused by excessive attention to the adverse effects of teacher-student competition. All in all, actively seeking the elements of teacher-student cooperation in the teacher-student conflicts and paying attention to the factors that affect teacher-student cooperation is a favorable attempt to deal with the problem of the teacher-student conflicts.

\subsection{Parents Construct a Harmonious Relationship between Teachers and Students, and Liberate the Minds of Teachers and Students}

The teacher-student conflict will inevitably affect the development of the teacher-student relationship. In the face of the teacher-student conflict, people can be hopeful or melancholy. When the teacher-student conflict is to promote teacher-student cooperation and consolidate the foundation of the teacher-student community, people are full of hope for the future of the teacher-student conflict. At this time, the teacher-student relationship is harmonious. When the teacher-student conflict is to show the teacher-student competition. When the struggle for the interests of teachers and students is manifested, people are sad about the future of the conflict between teachers and students. At this time, the relationship between teachers and students is tense. As one of the forces regulating the conflicts between teachers and students, as an important subject in the construction of a learning community, parents shoulder the dual mission of constructing a harmonious relationship between teachers and students and liberation of the minds of teachers and students, and play a bridge role in the common life of teachers and students. In the current classrooms in my country, projectbased group learning activities are being actively responded to and promoted. In Japan, classroom practice based on the learning community is also being quietly carried out. From these learning activities and practices, it can be found that the construction of a harmonious relationship between teachers and students based on cooperation is the interpersonal goal pursued by current education. From the perspective of the basic characteristics of an ideal teacher-student relationship, in order to construct a harmonious relationship between teachers and students, we first need to "respect teachers, love students and cooperate with each other". As teachers, we must love and care for students. As students, we must respect teachers, teachers and students. We must cooperate closely in our educational life. The second need is "democracy, equality, harmony and intimacy." As the main body of the teacher-student relationship, teachers and students must establish democratic concepts and equal dialogue. On this basis, teachers and students must maintain harmony with each other in their lives and establish close teach- 
ers and students relationship. Third, we need to "share and co-create, and teach each other". Teachers as the main body of teaching and students as the main body of learning need to share and create results together, and express themselves in sharing and creation. Teachers and students need to learn from each other in classroom practice, teaching each other, and teachers and students obtain continuous growth in learning. Judging from the reality of the teacher-student relationship in the current classroom, if a harmonious teacher-student relationship is to be constructed, firstly, parents need to observe the conflicting behavior of the teacher and student in the current classroom, and to find out the harmonious teacher-student relationship through direct confrontation and analysis of the teacher-student conflict. Influencing factors, so as to propose a strategy for the construction of a harmonious teacher-student relationship. Secondly, parents need to observe the student-student relationship in the current classroom, and judge the degree of construction of the teacher-student relationship through the understanding of the student-student peer relationship, especially the consciousness and spirit of group cooperation. Once a harmonious teacher-student relationship is constructed, then the minds of teachers and students will be liberated, teachers and students will no longer be bound and enslaved by traditional ideas, and teachers and students will achieve true freedom. "True freedom is that the individual freely administers thoughts, rather than being dominated by thoughts." (Cheng, 2016). Therefore, the teacher-student conflicts will cause educators to pay attention to the teacher-student relationship, and it will also promote classroom changes based on the construction of a harmonious teacher-student relationship. In practice, in the whole process, teachers and students have their own educational goals, that is, through the awareness of the teacher-student conflicts, seek the construction of a harmonious teacher-student relationship, realize the liberation of teachers and students' hearts, and promote the growth of teachers and students and create beauty Life of teachers and students.

\section{Conflicts of Interest}

The author declares no conflicts of interest regarding the publication of this paper.

\section{References}

Buber, M. (1965). Between Man and Man. Macmillian, 88.

Cheng, L. (2016). The Moral Foundation of Education-an Introduction to Educational Ethics. Fujian Education Press, 180.

Coser, L. (1989). The Function of Social Conflict. Sun, L. P. et al., Translated. China Publishing House, 5-7, 35, 79.

Huang, Z. J. (2003). Pay Attention to the Conflicts in Classroom Life-The Cultural Perspective. Academic Exploration, 7, 71-73.

Lu, Y. Q. (2012). Modern Western Educational Philosophy. Peking University Press, 200201.

Noddings, N. (2017). Philosophy of Education. Xu, L. X., Translated. Beijing Normal 
University Press, 185.

Russell, B. (2016). Russell Collection Vol. 2 Philosophical Issues Religion and Science. He, Z. W. (Philosophical Issues), Xu, Y. C., \& Lin, G. F. (Religion and Science) Translated, The Commercial Press, 97-98, 100.

Zhao, M. (2021). The Characteristics and Control Strategies of the Conflicts between Teachers and Students in Primary and Secondary Schools in the Context of New Immigrants. Educational Science Research, 3, 92-96. 